\title{
VANTAGEM COMPARATIVA REVELADA NAS EXPORTAÇÕES DE LÁCTEOS
}

\author{
Karina Aparecida dos Santos ${ }^{1}$, Nestor Pedro Furlanetto ${ }^{2}$ \\ Universidade Federal da Grande Dourados - UFGD ${ }^{1}$. Universidade do Oeste Paulista - UNOESTE, Presidente Prudente, \\ $\mathrm{SP}^{2}$. E-mail: karina admlupi@hotmail.com
}

\begin{abstract}
RESUMO
É importante identificar o papel do Brasil dentro do mercado internacional, analisando a evolução da produção e competitividade dos produtos lácteos frente aos principais players mundiais. Assim, estudo busca identificar a competitividade dos produtos lácteos brasileiros em paridade aos principais produtores e exportadores de derivados lácteos no mundo. Para atingir o objetivo proposto, este estudo baseou-se na metodologia de Índice de Vantagem Comparativa Revelada (IVCR). Os principais resultados obtidos neste estudo identificaram uma desvantagem comparativa nas exportações. Na média entre 2006 e 2014, o IVCR foi de 0,12 e 0,92 respectivamente. Um índice relativamente baixo, mas com base nos últimos resultados, o país conseguiu ampliar suas vantagens frente ás exportações. Tradicionalmente o Brasil é um grande produtor de leite e estimado como promissor no cenário lácteo mundial, no entanto, ainda é preciso desenvolver muito no que se refere às relações internacionais.
\end{abstract}

Palavras-chave: exportação; leite; derivados; lácteos; competitividade.

\section{REVEALED COMPARATIVE ADVANTAGE IN EXPORTS OF DAIRY}

\section{ABSTRACT}

It is important to identify the role of Brazil in the international market, analyzing the evolution of production and competitiveness of dairy products across the major world players. Thus, the study seeks to identify the competitiveness of Brazilian dairy products in parity to the main producers and exporters of dairy products in the world. To achieve this purpose, this study was based on Comparative Advantage Index methodology Revealed (IVCR). The main results obtained in this study identified a comparative disadvantage in exports. On average between 2006 and 2014, the IVCR was 0.12 and 0.92 respectively. A relatively low rate, but based on the latest results, the country managed to expand its front advantages ace exports. Traditionally Brazil is a major producer of milk and estimated as promising in the global dairy scenario, however, we still need to develop a lot in regard to international relations.

Keywords: export; milk products; dairy; competitiveness.

\section{INTRODUÇÃO}

A cadeia leiteira, no âmbito nacional e global, tem suas multíplices estruturas na competitividade das exportações ou nas políticas públicas para o setor (PINIOR et al., 2012). A competitividade nas exportações de lácteos é fator importante para a economia e garante a sustentabilidade em um ambiente de competitividade global (BOJNEC; FERTŐ, 2014).

Para o Brasil a cadeia láctea, exerce em seu processo funções que se estende a geração de empregos, fornecimento de alimentos a preços acessíveis a população, desenvolvimento social e mercado consumidor para bens industrializados. As condições naturais do país oferecem aos produtos agropecuários condições propícias para vantagens comparativas, e uma função de geração de divisas na compra bens de capital e matéria primas fundamentais para outras atividades econômicas (BRASIL. Ministério da Agricultura, Pecuária e Abastecimento, 2015).

O setor também desempenha um papel significativo para a economia do Brasil. Envolve 1,5 milhões de produtores, com produção de 33,37 bilhões de litro/ano, classificando-o como quinto maior produtor mundial de leite (INSTITUTO BRASILEIRO DE GEOGRAFIA E 
ESTATÍSTICA, 2011; UNITED STATES DEPARTMENT OF AGRICULTURE, 2014).

A atividade movimentou em 2015, aproximadamente $\mathrm{R} \$ 33,15$ bilhões/ano (valor bruto apenas na produção de leite), contribuindo principalmente para a economia de pequenas e médias cidades e emprega mais de 4 milhões de pessoas (SIQUEIRA et al., 2010). Para efeito de comparação, cada dólar de aumento no setor de produção agroindustrial do leite, sucede-se um acréscimo a cerca de cinco dólares no Produto Interno Bruto-PIB (VILELA, 2008).

No entanto, as exportações ainda são irrisórias, em 2015 a balança comercial de produtos lácteos encerrou com um déficit de 96,61 milhões de dólares, contudo um déficit inferior comparado ao ano de 2014 (101,6 milhões de dólares). Apesar do resultado negativo, 2015 obteve o melhor saldo na balança comercial. Tal cenário está elencado a uma redução nas exportações de $12 \%$ em volume, mas a receita foi maior, passando de US\$275,75 milhões para US\$278,04 milhões (BRASIL. Ministério do Desenvolvimento, Indústria e Comércio Exterior, 2014).

Iniciativas públicas e ações privadas desenvolvem medidas com o propósito de aumentar as exportações e gerar maior competitividade para o setor. As exportações geram a força motriz por trás do desenvolvimento, como fonte de crescimento, baseado em suas externalidade de efeitos positivos para difusão tecnológica gerada pelas exportações (EDWARDS, 1993).

Países em desenvolvimento que mantém suas inter-relações e suas exportações, estão mais integrados com o mercado e possuem uma vantagem em tecnologia gerada pelos países mais avançados. Um país que promove suas exportações se move para possibilidades de fronteira se igualando ao mercado internacional e transformação interna (LEWIS, 1955).

A mensuração da vantagem comparativa dos produtos nacionais frente aos principais players mundiais ocorrerá através da metodologia de Índice de Vantagem Comparativa Revelada (IVCR). Para complementar a discussão será realizada uma análise da balança comercial brasileira de produtos lácteos, evidenciando as principais políticas públicas e ações privadas para aumentar a produtividade do setor e competitividade nas exportações dos principais produtos lácteos transacionados.

Neste contexto, o objetivo do estudo foi identificar a competitividade dos produtos lácteos brasileiros em paridade aos principais produtores e exportadores de derivados lácteos no mundo (Argentina, Alemanha, Brasil, Estados Unidos e Nova Zelândia).

\section{METODOLOGIA}

A metodologia de Vantagem Comparativa Revelada (IVCR) mensura o índice de participação de um país para determinado produto, na pauta de exportações no mercado externo. 0 desempenho significativo do país nas exportações pode representar desenvolvimento, aplicação do capital privado e crescimento para o setor (BALASSA, 1977; SIQUEIRA; PINTO, 2012).

Para calcular o índice de IVCR é utilizada a seguinte formula:

$$
\operatorname{IVCRiz}=\left(\frac{X i j}{X i}\right) /\left(\frac{X w j}{X w}\right)
$$

IVCRiz : representa a vantagem comparativa revelada nas exportações do produto i no país;

$X i j$ i valor das exportações do país no produto $j$;

$X i$ representa o valor total das exportações do país

$X w j$ aponta o valor total das exportações mundiais do produto $j$;

$X w$ demonstra o valor total das exportações mundiais.

Se o IVCR apresentar um índice superior a 1 , o país mantém vantagem comparativa nas exportações do produto, caso o índice calculado seja inferior a 1 o país não apresenta vantagem comparativa nas exportações mundiais do produto calculado. Os dados de exportações usados para mensuração dos índices foram pesquisados através do COMTRADE e ANUALPEC.
Os produtos analisados obedeceram a Nomenclatura Comum do MERCOSUL (NCM), para exportação de produtos lácteos (manteiga, leite/creme de leite em pó, queijo e leite/creme de leite fluído). O período analisado pelo trabalho corresponde aos anos de 2006 e 2014, entretanto para o último ano os dados encontram-se incompletos devido à indisponibilidade de dados 
de alguns países. Portanto para o ano de 2014 ainda tratam-se de estimativas. A escolha do período foi influenciada devido às diversas transformações que o setor nacional sofreu na última década. Em 2002 se deu inicio a estabilização econômica e abertura para novos mercados. No entanto em 2008 o mercado internacional passou por uma crise econômica, até inicio de sua recuperação, possíveis oscilações e recuperação do mercado.

Os países analisados foram Argentina, Alemanha, Brasil, Estados Unidos e Nova Zelândia. Principais produtores e exportadores de derivados lácteos. E por fim discutiram-se os resultados obtidos que contribuíram na inferência das conclusões, para explicar as variações dos índices.

\section{RESULTADOS}

Na tabela 1 são apresentados os índices de vantagem comparativa revelada, em países selecionados, subdivididos por derivados lácteos. $O$ índice é referente ao total das exportações por cada país (Estados Unidos, Brasil, Nova Zelândia, Argentina e Alemanha), elencado abaixo.

Tabela 1. Índices de vantagem comparativa nas exportações por categorias de determinados derivados lácteos (2006 e 2014).

\begin{tabular}{lccccccccccc}
\hline & \multicolumn{2}{c}{ Alemanha } & \multicolumn{2}{c}{ Argentina } & \multicolumn{2}{c}{ Brasil } & \multicolumn{2}{c}{ EUA } & \multicolumn{2}{c}{ Nova Zelândia } \\
\cline { 2 - 12 } & 2006 & 2014 & 2006 & 2014 & 2006 & 2014 & 2006 & 2014 & 2006 & 2014 \\
\cline { 2 - 12 } & 0,64 & 0,58 & 2,23 & 1,37 & 2,21 & 3,85 & 0,32 & 0,96 & 1,68 & 2,53 \\
Leite/creme de leite (pó) & Leite/creme de leite & 1,45 & 1,83 & 0,16 & 0,22 & 0,20 & 0,23 & 1,47 & 2,01 & 0,18 & 0,29 \\
(fluído) & & & & & & & & & & \\
Manteiga & 0,47 & 0,72 & 0,43 & 0,98 & 0,18 & 0,32 & 0,18 & 1,24 & 2,36 & 2,87 \\
Queijo & 0,96 & 1,54 & 0,37 & 0,64 & 0,86 & 1,04 & 0,44 & 0,96 & 0,66 & 0,34 \\
\hline
\end{tabular}

Fonte: Elaborado pelos autores.

Neste caso, é interessante analisar os aspectos característicos de cada país, para posteriormente entendermos como o Brasil está inserido neste contexto e seu posicionamento de mercado.

Em destarte, a Nova Zelândia é um dos países que, reconhecidamente, mais se destacou em cooperativismo e conseguiu desenvolver o setor lácteo o tornando numa grande fonte de divisa. O país é o primeiro exportador de manteiga, segundo maior exportador de leite em pó desnatado e queijo, produzindo em 2015 mais de 22 bilhões de litros de leite, segundo a Organization for Economic Cooperation and Developmente Food and Agriculture Organization - OCDE/FAO (2013). Sua participação atual nas exportações de lácteos é de $32,4 \%$ e $95 \%$ da sua produção é destinada ao mercado externo. Dessa forma, como é possível observar na Tabela 1, os maiores índices de VCR estão atribuídos à Nova Zelândia. O país garante sua posição como exportador mundial, com base em pesquisa, melhoramento genético, saneamento e planejamento produtivo.

No entanto, na América do Sul, a Argentina desempenhava esse papel representativo no mercado mundial de derivados lácteos. Ainda assim, o país perdeu força nas exportações na última década. Suas vantagens produtivas em redução de custos e os melhores índices de produtividade, não foram suficientes para amortizar uma série de problemas macroeconômicos que o país enfrentou. Entre essas dificuldades, ressaltam-se planos econômicos mal sucedidos, câmbio depreciado em relação ao dólar, altos índices de inflação e restrições das exportações de leite em pó, por parte do governo. Esses obstáculos na economia do país refletiram significativamente no IVCR, entre os produtos estudados, acarretando em uma redução de $28 \%$ do IVCR.

Entre os países analisados a Alemanha demonstrou uma maior estabilidade em assegurar as exportações de derivados lácteos. Além de ser uma das maiores e mais sólidas economias do mundo, em determinados períodos houve uma pequena redução no IVCR. Mas essa atenuação nos resultados pode ser justificada pelo acréscimo nas exportações de outros produtos, uma vez que o IVCR é fracionado pelo valor total das exportações do país. No caso do IVCR da Alemanha para o leite/creme de leite em pó passou de 0,64 em 2006 para 0,58 em 2014. Entre os produtos estudados, foi o único que 
demonstrou uma leve queda em relação aos outros derivados.

Vale ressaltar que o país também se configura um grande importador de produtos lácteos. Isso acontece pelo acordo comercial entre os países membros da União Europeia (UE), onde prevalece a livre transição de mercadorias. A Alemanha se beneficia do custo-benefício, onde a vantagem é importar de outros países membros, cujo custo de produção seja inferior. Apesar de o país apresentar vantagem comparativa e, sua representatividade nas exportações mundiais, em contraste a outros países, não é tão competitivo.

Por sua vez, os resultados do IVCR dos Estados Unidos revelaram que o país não possui vantagem comparativa em relação a outros países exportadores de produtos lácteos. Já que o seu IVCR para as exportações de queijo, por exemplo, foi de 0,44 em 2006 para 0,96 em 2014. Parte desse resultado pode ser elencado as exportações de queijo para a Coreia do Sul, que desde 2010 aumentaram em 400\% (UNITED STATES DEPARTMENT OF AGRICULTURE, 2016). O mercado asiático impulsionaram as exportações americanas. Somente a China é responsável por importar $14,0 \%$ dos produtos lácteos no panorama mundial. Contudo em relação às projeções de crescimento na produção são baixas, estimadas em $1,7 \%$ ao ano pela Organization for Economic Cooperation and Developmente Food and Agriculture Organization - OCDE/FAO (2013). Em contrapartida, as projeções para as exportações, são de um acréscimo de $22,3 \%$ até 2023.

\section{DISCUSSÃO}

Para analisar a conjuntura atual das exportações de lácteos brasileiras, é preciso antes estudar os aspectos que proporcionaram esta fase estacionária do setor. Ao analisar o histórico de produção brasileira é possível verificar que o Brasil passou por profundas transformações, e relativamente é um país "novo" em aspectos de comercialização. $\mathrm{Na}$ década de 90, o setor da bovinocultura leiteira passou por um processo de transição, que foi o fim do tabelamento de preços do leite, tanto em nível de produtor quanto ao consumidor, que vigorava desde 1945 (MAGALHÃES, 2007).

Com o setor estagnado desde 1945 a 1991, a condição mínima de desenvolvimento para a cadeia leiteira seria a modernização, para tornar o produto brasileiro mais competitivo com os produtos importados e principalmente exportar para explorar novos mercados. Iniciativas começaram a ser adotadas tanto pelo governo para incentivar o consumo, quanto da iniciativa privada para melhorar a qualidade, tecnologia e produtividade (VILELA, 2008).

Quando se passou quase meio século de tabelamento o setor se desvencilhou do governo, foi quando iniciou a independência para o setor. Entretanto, isso trouxe prejuízos e atrasos significativos para o agronegócio do leite - o tabelamento foi usado mais como controle de inflação do que para estimular a produção.

Os empresários não investiam em um setor controlado pelo governo, desestimulava a aplicação de capital dentro da cadeia, além de atrasar a cultura de negociação entre os produtores. Até hoje o setor sente os reflexos desse atraso, é possível identificar a falta de coordenação e comunicação entre os elos - no qual ainda obtemos melhoras consideráveis.

Com o Plano Real instalado em 1994, iniciou-se uma estabilidade econômica no país, que trouxe benefícios a todos os setores, principalmente do agronegócio do leite. Com a estabilidade houve um estimulo a demanda, ao crescimento e desenvolvimento da população, elevando a renda e o poder de consumo.

Todavia, com abertura comercial o preço do leite ficou refém das oscilações de preço dependente da balança comercial, o que reduziu significativamente as margens de lucro do produtor, que oscilam em determinados períodos com custos elevados e preços que não acompanham esta inconstância. Esta redução de margem gerou dificuldades para todo o setor, "forçando" o produtor a adotar medidas de produção mais eficiente (SANTOS; BARROS, 2006).

As importações brasileiras de leite foram importantes para a complementação da produção doméstica. As importações geram o intercambio comercial intra-indústria e tornam mais eficientes as exportações de outros produtos e importação de outros derivados. 0 crescimento da renda foi um indicador importante para demonstrar que o incremento nas importações, e torna mais evidente que o setor nacional tem uma dificuldade em atender um crescimento rápido na demanda interna.

Mas antigos problemas atrasam o desenvolvimento e competitividade deste setor, dificuldades em infraestrutura, qualidade do leite e, principalmente, relações internacionais. Em 
um país que possui condições propícias para aumentar e melhorar a produtividade, como custos baixos, disponibilidade de terra e água para a produção. Em países como Europa, América do Norte e Oceania, percebe-se que a produção leiteira é proporcionalmente mais desenvolvida economicamente, o que reflete é a importância da produtividade no incremento da população. Ou seja, os grandes provedores de leite no mundo continuam sendo nações que investem em melhoria da qualidade durante todo o processo produtivo (SIQUEIRA; PINHA, 2012).

\section{CONCLUSÃO}

Diante do exposto, é possível analisar que mesmo depois de uma década do fim do tabelamento de preços e instabilidade econômica, o Brasil aumentou sua produção em $74 \%$. Entretanto os índices de produtividade ainda são baixos comparados aos dos principais produtores mundiais, mas tem potencial para

\section{REFERÊNCIAS}

BALASSA, B. 'Revealed' Comparative Advantage Revisited: An Analysis of Relative Export Shares of the Industrial Countries, 1953-1971. The Manchester School of Economic \& Social $\begin{array}{lllll}\text { Studies, } & \text { v. 45, n. 4, } 1977 .\end{array}$ https://doi.org/10.1111/i.1467-

9957.1977.tb00701.x

BOJNEC, Š.; FERTŐ, I. Export competitiveness of dairy products on global markets: The case of the European Union countries. Journal of Dairy Science, v. 97, n. 10, p. 6151-6163, 2014. https://doi.org/10.3168/jds.2013-7711

BRASIL. Ministério da Agricultura, Pecuária e Abastecimento. Projeções do Agronegócio: Brasil 2012/13 a 2022/23. 2015. Disponível em: <http://www.agricultura.gov.br/arq_editor/proje coes\%20-\%20versao\%20atualizada.pdf>. Acesso em: 12 de Julho de 2015.

BRASIL. Ministério do Desenvolvimento, Indústria e Comércio Exterior. Exportação de Lácteos. Disponível em: < http://www.mdic.gov.br/sitio/interna/interna.ph $p$ ?area $=1 \&$ menu=1728 $>$. Acesso em: 14 de Julho de 2014.

EDWARDS, S. Openness, trade liberalization, and growth in developing countries. Journal of aumentar muito mais, já que o crescimento médio anual de leite brasileiro está equivalente à produção mundial.

Analisando a demanda o cenário é favorável para os próximos anos, tanto pelo consumo interno, quanto para as exportações de lácteos, a China e Índia estão impulsionando o consumo internacional. A China em 2014 aumentou suas exportações de leite em pó de 56 mil toneladas para 112 mil toneladas.

Outro problema que ainda deve ser corrigido pelo Brasil é diversificação do rebanho, falta de padronização na qualidade do leite e desorganização da cadeia. Por fim, a demanda por produtos lácteos deve-se aumentar para os próximos anos, principalmente $\mathrm{O}$ consumo doméstico, o Brasil tem potencial para atender a demanda, entretanto precisa de maiores investimentos tanto do setor privado quanto ao setor público, para que efetivamente ocupe sua posição como um grande exportador de lácteo.

economic Literature, v. 31 , n. 3, p. 1358-1393, 1993.

INSTITUTO BRASILEIRO DE GEOGRAFIA E ESTATÍSTICA. Estatística da Produção da Pecuária. Disponível em: <http://www.ibge.gov.br/home/estatistica/indica dores/agropecuaria/producaoagropecuaria/abat e-leite-couro-ovos_201301_publ_completa.pdf>. Acesso em: 14 jul. 2014.

LEWIS, W. Arthur. Theory of economic growth. Routledge, 2013.

MAGALHÃES, R. S. Habilidades sociais no mercado de leite. Revista de Administração de Empresas, v. 47, n. 2, p. 1-11, 2007. https://doi.org/10.1590/S0034-

$\underline{75902007000200003}$

ORGANIZATION FOR ECONOMIC COOPERATION AND DEVELOPMENTE FOOD AND AGRICULTURE ORGANIZATION. Agricultural Outlook 2014-2023. $2013 . \quad$ Disponível em: <http://www.oecd.org/site/oecdfaoagriculturaloutlook/>. Acesso em: 12 de Julho de 2014.

PINIOR, B. et al. The trade network in the dairy industry and its implication for the spread of contamination. Journal of dairy science, v. 95, n. 
11,

p.

6351-6361,

2012.

https://doi.org/10.3168/ids.2012-5809

SANTOS, D. F.; BARROS, G. S. C. Importações brasileiras de leite: impactos micro e macroeconômicos. Economia Aplicada, v. 10, n. 4, p. 541-559, 2006. https://doi.org/10.1590/S1413$\underline{80502006000400004}$

SIQUEIRA, K. B.; PINHA, L. C. Vantagens comparativas reveladas e o contexto do Brasil no comércio internacional de lácteos. Informações Econômicas, v. 42, n. 3, p. 40-49, 2012.

SIQUEIRA, K. B. et al. O mercado lácteo brasileiro no contexto mundial. Embrapa Gado de Leite Circular Técnica, n. 104, 2010.

UNITED STATES DEPARTMENT OF AGRICULTURE. Milk Production. 2014. Disponível em: <http://www.nass.usda.gov/Publications/Todays _Reports/reports/mkpr0514.pdf>. Acesso em: 12 de Julho de 2014.
UNITED STATES DEPARTMENT OF AGRICULTURE. The 2016 National Trade Estimate Report. Disponível em: <https://ustr.gov/sites/default/files/2016-NTEReport-FINAL.pdf> Acesso em: 12 ago. 2016.

VILELA, D.; BRESSAN, M.; CUNHA, A. S. Cadeia de Lácteos no Brasil. 1.ed. Minas Gerais: Embrapa Gado de Leite, 2008.

Recebido para publicação em 19/12/2016 Revisado em 18/02/2017

Aceito em 27/03/2017 